\title{
Treatment of Secondary Fly Ash by Commercial Size MF Furnace System
}

\author{
Takashi Yoshida $^{(1)}$, Hidenori Nagai ${ }^{(2)}$ and Shinji Noda ${ }^{(3)}$ \\ ${ }^{(1)}$ MS Zinc Co., Ltd \\ 18-16 Shinbashi, Minato-ku, Tokyo, 105-0004,Japan \\ TEL:81-3-3591-3110 \\ e-mail:tyoshida@msz.jp \\ ${ }^{(2)}$ Mitsui Mining and Smelting Co., Ltd \\ ${ }^{(3)}$ Miike Smelting Co.
}

(Received January 7, 2004; final form January 28, 2004)

\begin{abstract}
Secondary fly ash generated from a municipal waste treatment process is mainly treated by stabilization and land filling. It includes non-ferrous metals, such as zinc and lead. Thus its treatment is important not only because of environmental problems but also for preservation of mineral resources. Melting treatment by the MF process is one of the most promising methods for secondary fly ash in order to recover non-ferrous metals and to prevent environmental problems. A laboratory scale test has already been done and it seems to be an effective method for secondary fly ash. The treatment test by using a commercial size MF process has been studied to determine the feasibility of the MF process in practical use. The test operation was successful without any difficulties or problems. The recovery rates were $\mathbf{9 0 . 1 \%}$ and $\mathbf{9 8 . 7 \%}$ for zinc and lead, respectively. The slag can be used in the cement industry based on the leaching test of heavy metal elements. Also, the decomposition rate of dioxin was more than $99.8 \%$.
\end{abstract}

Key Words: Secondary fly ash, MF process, nonferrous metal, recycle, zinc, lead, slag, leaching test

\section{INTRODUCTION}

Fifty million tons of municipal wastes are generated every year in Japan. The incineration process has become the most popular method for treatment of municipal waste. Slag and fly ash are generated in the incineration process. Slag can be used as a road construction material; however, fly ash includes dioxin and heavy metal, thus the treatment of fly ash is an important issue. Its treatment is strictly controlled by regulations. Stabilization followed by landfill is widely applied. Recently the melting process has been recommended for the treatment of fly ash in order to prevent problems caused by heavy metals as well as dioxin. The fly ash melting process seemed to be the most effective process from the point of view of long range-stability and shortage of land-fill area. The melting process of the fly ash makes it possible to reduce the volume of waste and also to decompose the dioxin. However, the melting process of fly ash generates secondary fly ash. The secondary fly ash includes some non-ferrous metals, such as lead and zinc; thus, the treatment of secondary fly ash is also very important from the point of view of not only the environmental problems, but also the conservation of mineral resources. Few processes have been reported $11,2 /$ for the effective treatment of secondary fly ash. 
Thus, the authors have studied treatment of secondary fly ash by a pyro-metallurgical process. Results of the laboratory and bench-scale tests /3-6/ have been reported. These test results suggested that the treatment of secondary fly ash by the MF process would be promising. A treatment test by using a commercial size MF process has been carried out to determine the feasibility of the secondary fly ash treatment on a commercial-scale. This paper reports the test results of a commercial-scale melting test.

\section{EXPERIMENT}

\subsection{Test sample}

Three kinds of secondary fly ash, hereinafter SFA, were used for the tests. An SFA generated by an electrothermal furnace and two kinds of SFAs from fluidizedbed-type gasified melting furnaces were used. The chemical compositions of the SFAs used for the test are shown in Table 1, where the SFA-A was generated by the commercial-scale electrothermal melting furnace of fly ash, SFA-B and SFA-C were generated by different commercial-scale gasified melting furnaces. SFA generally includes rather large amounts of chlorine, which causes corrosion problems in the pyrometallurgical processing facilities. Thus chlorine should be eliminated before melting treatment by a washing method to prevent corrosion problems. The chlorine contents of the SFAs were $23.8 \%$ (SFA-A), 9.8\% (SFA-B B) and $19.8 \%$ (SFA-C), i.e., they varied widely. The zinc contents of SFA varied from $2 \%$ to $12 \%$ and the lead contents rom $0.5 \%$ to $4.7 \%$. These values would reflect different treated wastes, processes and

Table 1

Chemical composition of the secondary fly ash (SFA) used for the test (mass \%)

\begin{tabular}{llll}
\hline Sample & $\mathrm{Cl}$ & $\mathrm{Zn}$ & $\mathrm{Pb}$ \\
\hline SFA-A & 23.8 & 12.2 & 4.7 \\
SFA-B & 9.6 & 7.4 & 1.4 \\
SFA-C & 19.8 & 2.4 & 0.5 \\
\hline
\end{tabular}

operating conditions. These differences should be taken into consideration when the treatment process of SFA is considered.

\subsection{Experimental procedure}

Figure 1 shows the schematic flow diagram of a commercial-size MF process, and a schematic illustration of the MF furnace is shown in Figure 2. Table 2 shows the specification of a commercial-size MF process. Several reports /7-12/ have already been presented regarding the operation of an MF process so that it is not necessary to explain the MF process. Originally the MF process was developed for treatment of zonc-containing residues generated in the vertical retort zinc smelting process. The vertical retort process has not been operated for almost 20 years. Since then the treatment of industrial waste, such as electric arch furnace dust (EAF dust), has utilized the existing procedure.

The washing test was carried out followed by the melting test of SFA by using a commercial-scale MF process. The test flow of chlorine elimination by a twostep washing method is shown in Figure 3 . The influence of halogen on the recycling process $/ 13,14$ / has been reported. Halogen elements cause corrosion problems as mentioned above; thus they should be eliminated before pyro-metallurgical processing. Three kinds of SFA are washed and leached in a water-base liquid at $\mathrm{pH} 10$ controlled with $\mathrm{NaOH}$. Then they are filtered through a filter press to reduce the moisture content. The residue (filter cake) is washed again. The chlorine contents of SFA after the two-step washing test was measured by using an Induced Coupled Plasma Analyzer (ICP). The chlorine elimination ratio was determined based on the analytical values.

The dehalogenated SFAs were stocked in a storage bin and fed to the preparation section of the MF process. The amount of feed was controlled by a computer system on the basis of conditions equal to those of normal commercial operation. They were mixed with other raw materials, coal as a reducing reagent and silica sand as a flux to control the slag composition. The other raw materials included EAF dust and some other kinds of waste. In this test operation the treated amount of SFA was controlled to be $10 \%$ of the total amount of 


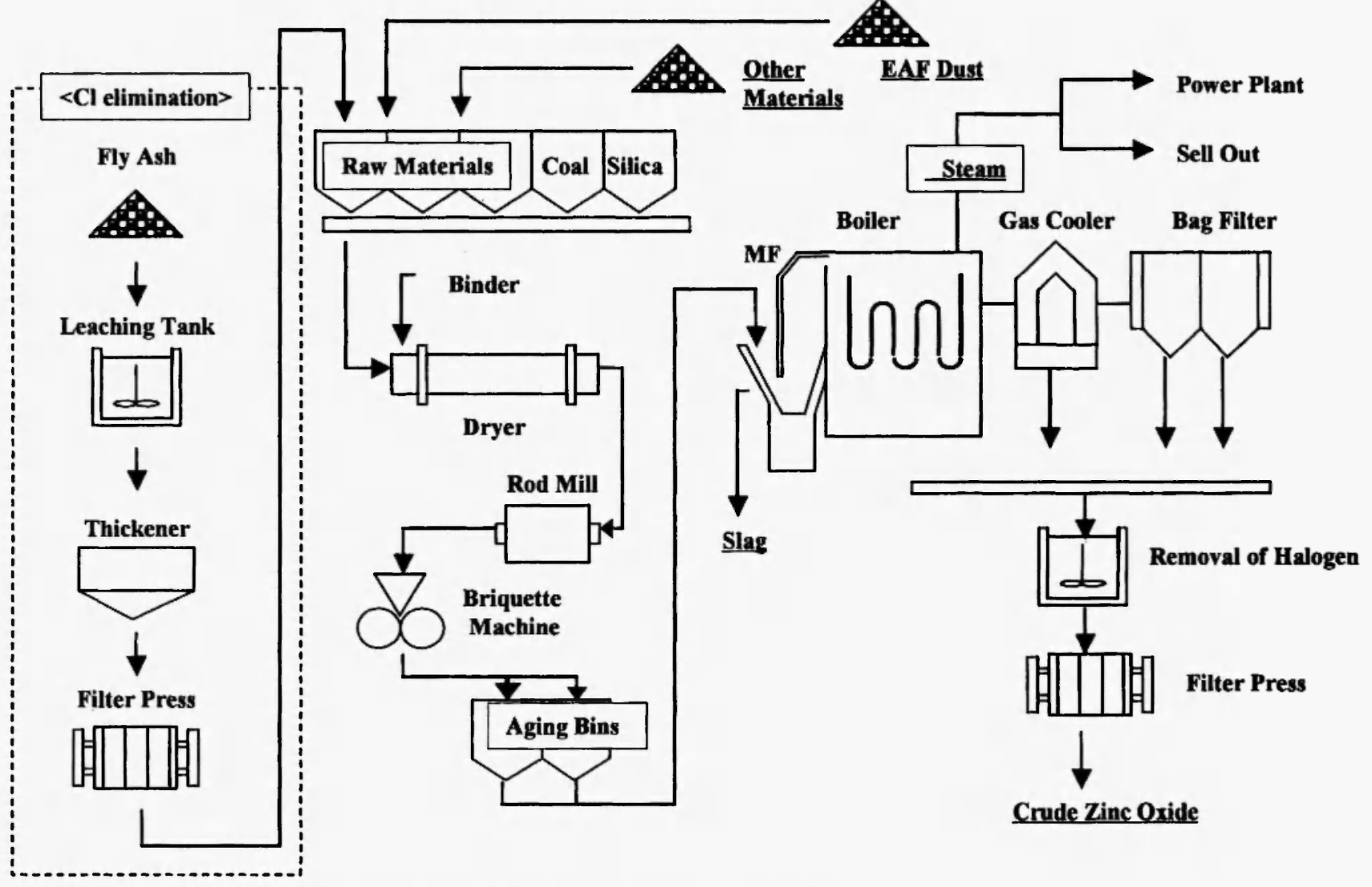

Fig. 1: Schematic flow diagram of MF process

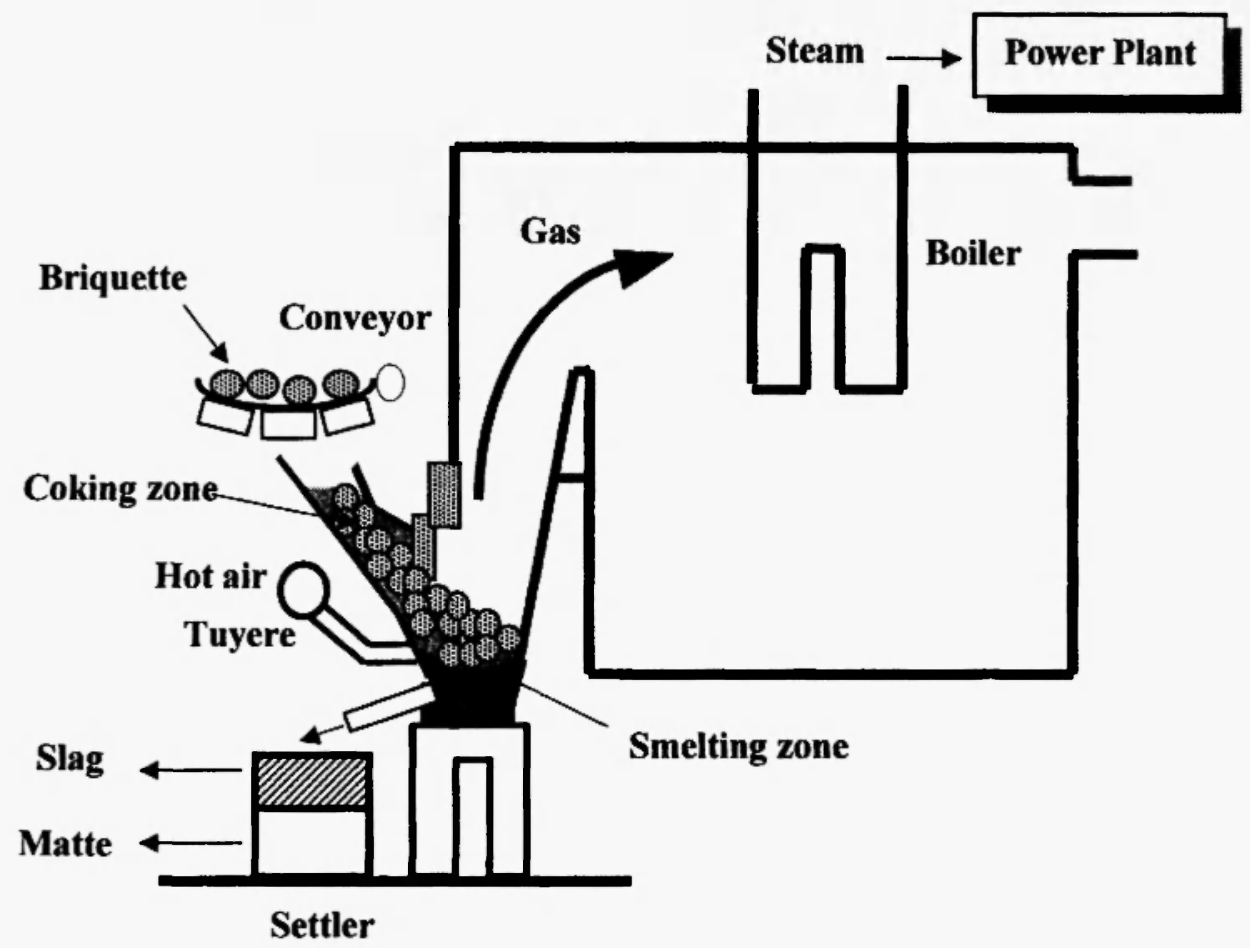

Fig. 2: Schematic illustration of MF furnace 
Table 2

Specification of commercial size MF process

\begin{tabular}{|c|c|}
\hline Equipment & Specification \\
\hline MF Furnace & $\begin{array}{l}\text { Rectangular Type Half Shaft Furnace, } 7.8 \mathrm{~m}(\mathrm{~W}) \times 1.2 \mathrm{~m}(\mathrm{~L}) \times 12.2 \mathrm{~m}(\mathrm{H}) \\
\text { Cap. } 160 \times 10^{3} \mathrm{t} / \mathrm{y} \text { as Briquette }\end{array}$ \\
\hline Stock Bins & $100 \mathrm{~m} 3 / \mathrm{bin}: 3$ bins, $70 \mathrm{~m} 3 / \mathrm{bin}: 14 \mathrm{bins}$ \\
\hline Dryer & Rotary Type, $3.0 \mathrm{mf} \times 25 \mathrm{~m}(\mathrm{~L})$, Cap. $25 \mathrm{t} / \mathrm{h}$, Fuel:Waste Oil \\
\hline Mill & Rod mill, $2.4 \mathrm{mf} \times 3.6 \mathrm{~m}(\mathrm{~L})$, Cap: $25 \mathrm{t} / \mathrm{h} \times 2 \mathrm{mills}$ \\
\hline Briquette Machine & $\begin{array}{l}\text { Double Roll Type } 1.0 \mathrm{mf} \times 0.35 \mathrm{~m}(\mathrm{~W}) \times 2 \text { sets, } 360 \text { pockets } / \mathrm{set}, 4 \text { machines } \\
\text { Cap. } 20 \mathrm{t} / \mathrm{h} \text { - machine, Size of Briquette: } 65 \times 80 \times 40 \mathrm{~mm}\end{array}$ \\
\hline Boiler & $\begin{array}{l}\text { Lamont Type Waste Gas Boiler, Heat Exchange Area: } 2567 \mathrm{~m} 2 \\
\text { Vapor Generation:23.3t/h at } 46 \mathrm{~kg} / \mathrm{cm} 2,733 \mathrm{~K}\end{array}$ \\
\hline Power Plant & Cap, $6500 \mathrm{kw}$, Normal Operation:4800kw \\
\hline Bag House & Waste Gas of MF Furnace: 2 Bag Houses, Filtering Area $3240 \mathrm{~m}^{2}, 2400 \mathrm{~m}^{2}$ \\
\hline Filter Press & $\begin{array}{l}\text { 3 Filter Presses, Filtering Area } 1500 \mathrm{~mm} \times 1500 \mathrm{~mm} \times 26\left(94 \mathrm{~m}^{2}\right) \text {, } \\
1500 \mathrm{~mm} \times 1500 \mathrm{~mm} \times 50\left(178 \mathrm{~m}^{2}\right), 1000 \mathrm{~mm} \times 1000 \mathrm{~mm} \times 18\left(30 \mathrm{~m}^{2}\right)\end{array}$ \\
\hline Effluent Treatment & Cap. $6500 \mathrm{~m}^{3} / \mathrm{d}$, Normal Operation: $1500 \mathrm{~m}^{3} / \mathrm{d}$ \\
\hline Emission Gas Treatment & $\mathrm{NaOH}$ Absorbing Type, Cap. $150000 \mathrm{~m}^{3} / \mathrm{h}$ \\
\hline
\end{tabular}

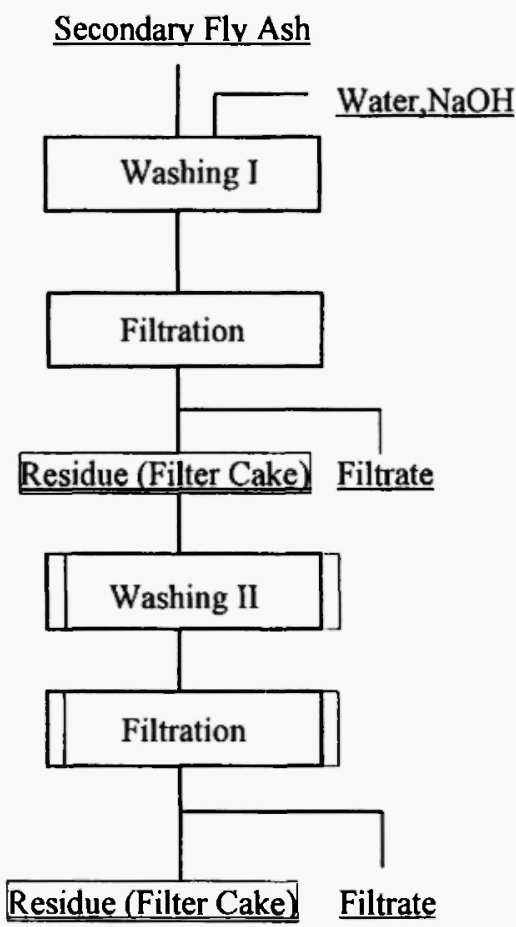

Fig. 3: Test flow of chlorine elimination from secondary fly ash by 2 -step washing method raw materials. The total capacity of a commercial-base $\mathrm{MF}$ process is approximately 100,000 tons/year; therefore, treatment of 10,000 tons/year of SFA by the commercial-base MF process was carried out in this study.

The blending sheet of the feed materials is shown in Table 3 for both the melting test operation and typical normal operation. The iron concentrate from the $\mathrm{Cu}$ smelting process was added to control iron content in the slag, because the iron content in EAF dust is higher than in the SFA. Based on the blending sheet, the melting test operation ran for 11 days and the amount of treated SFA was approximately 300 tons. In the chlorine elimination test, the chlorine compounds were dissolved in the liquid phase; thus the actual amount of charge to the MF furnace was about 220 tons during the test operation.

Samples of briquette, slag and crude $\mathrm{ZnO}$ were taken periodically to analyze the chemical compositions. Also examination by $\mathrm{X}$-ray diffractions and observation by SEM and EPMA were carried out. The operation 
Table 3

Blending materials of briquette

\begin{tabular}{lrrrr}
\hline \hline & \multicolumn{2}{c}{ Test Operation } & \multicolumn{2}{c}{ Normal Operation } \\
\cline { 2 - 5 } & Charge(t/d) & Ratio(\%) & Charge(t/d) & Ratio(\%) \\
\hline EAF Dust & 138.4 & 34.4 & 198.0 & 45.4 \\
Other Material & 98.0 & 24.3 & 98.7 & 22.5 \\
Secondary Fly Ash & 20.0 & 5.0 & 0.0 & 0.0 \\
SiO2 & 8.6 & 2.1 & 11.3 & 2.6 \\
Fe Ore & 17.2 & 4.3 & 12.9 & 3.0 \\
Coal & 102.0 & 25.3 & 95.5 & 21.9 \\
Binder & 18.4 & 4.6 & 20.0 & 4.6 \\
\hline Total & 402.6 & 100.0 & 436.4 & 100.0 \\
\hline
\end{tabular}

parameter data, indicating the condition of the commercial-size MF furnace, were collected and examined. The operating data, such as blast air volume and temperature, slag generation and its temperature, were carefully monitored to determine the operating conditions during the melting test. Also the amount of crude zinc oxide and its chemical composition were determined. The extraction test of slag generated during the melting test was carried out on a regulation basis to find out the effective method for slag utilization.

\section{TEST RESULTS AND DISCUSSION}

\subsection{Chlorine elimination test by the washing method}

The results of chlorine elimination test by using the three kinds of SFA are summarized in Table 4. The chlorine contents of the three samples before the washing showed a wide spread. The chlorine elimination ratio after the first-stage washing step was approximately 88 to $98 \%$ in each SFA. The chlorine elimination ratio after the second step washing treatment reached 94 to $99 \%$, which is a rather high elimination ratio. The chlorine elimination ratio after two-steps of washing treatment seemed to be independent of the initial chlorine content of SFA. This is because the chlorine compounds included in each SFA are almost similar, thus the solubility of chlorine is almost equal. The chlorine elimination ratio was calculated on the basis of Equation (1). In this equation, Vo indicates the chlorine amounts included in SFA before the washing test and $\mathrm{Va}$ indicates the amount after the washing test.

$\delta=(1-\mathrm{Va} / \mathrm{Vo}) \times 100$

The effectiveness of the two-step washing method has already been verified by a laboratory scale test. Furthermore, it was proved that this method was also effective in the commercial-scale operation. In the commercial MF operation, the chlorine content of the EAF dust, which is the main raw material, is less than $1 \%$ after chlorine elimination to prevent the corrosion problem. In this test the chlorine contents of each SFA were less than $1 \%$ after the two-step washing method; thus even for the commercial operation, the two-step washing method is effective in preventing corrosion problems. The chlorine elimination ratio seemed to be almost constant, but careful examination showed that they were slightly different. These differences were caused by the chlorine compound. SFA-A shows a very 
Table 4

Test result of chlorine elimination by two-step washing method

\begin{tabular}{lcccc}
\hline \hline Sample & Amount(10 $\left.{ }^{3} \mathrm{~kg}\right)$ & $\mathrm{Cl}$ content(mass\%) & $\mathrm{Cl}$ amount (10 $\left.{ }^{3} \mathrm{~kg}\right)$ & Cl Elimination (\%) \\
\hline SFA-A & 70.5 & 23.7 & 16.7 & \\
1st wash Cake & 49.1 & 0.48 & 0.236 & 98.6 \\
2nd Wash Cake & 44.1 & 0.44 & 0.194 & 98.8 \\
\hline SFA-B & 101.7 & 9.6 & 9.76 & \\
1st wash Cake & 84.2 & 1.35 & 1.14 & 88.4 \\
2nd Wash Cake & 78.8 & 0.77 & 0.61 & 93.8 \\
\hline SFA-C & 77.5 & 19.8 & 15.35 & \\
1st wash Cake & 52.9 & 2.5 & 1.322 & 91.38 \\
2nd Wash Cake & 52.2 & 0.65 & 0.339 & 97.8 \\
\hline
\end{tabular}

large chlorine elimination ratio even in the 1st step washing treatment. The peaks of $\mathrm{NaOH}, \mathrm{KCl}$ and $\mathrm{K}_{2} \mathrm{ZnCl}_{2}$ were observed by X-ray diffraction of SFA-A. These compounds dissolve easily into the aqueous phase, so that SFA-A shows a very high chlorine elimination ratio. An accurate study of the chlorine compounds in each SFA is necessary to determine the difference in the chlorine elimination ratio.

\subsection{Melting test results}

The chemical analysis of a briquette for the melting test is shown in Table 5 compared to that of normal operation. The lime content in the test operation briquette is higher and the chlorine content is lower than in the usual operation. In commercial operation, EAF dust is washed in alkali solution to eliminate chlorine. The chlorine content in EAF dust after the washing treatment is almost $1 \%$. On the other hand, the chlorine content of SFA after washing is lower (0.4-0.7\%) than in the EAF dust. This is the reason why the chlorine content in the briquette is lower than that of the usual operation.

The strength of briquette is also very important for

Table 5

Typical composition of briquette (mass $\%$ )

\begin{tabular}{lccccccc}
\hline \hline & $\mathrm{Zn}$ & $\mathrm{Pb}$ & $\mathrm{Fe}$ & $\mathrm{SiO}_{2}$ & $\mathrm{CaO}$ & $\mathrm{Al}_{2} \mathrm{O}_{3}$ & $\mathrm{Cl}$ \\
\hline Test Operation & 15.3 & 1.60 & 16.2 & 10.17 & 3.20 & 2.76 & 0.84 \\
Normal Operation & 15.0 & 1.53 & 17.0 & 10.20 & 2.34 & 2.67 & 0.98 \\
\hline
\end{tabular}


treatment of SFA by the MF process. The authors have already studied the strength of the briquette by using SFA in a laboratory scale test. The previous studies suggested that the moisture content and the amount of binder added are very important for the strength of the briquette. The compression strength of the briquette for the melting test was measured and the average value was $42.4 \mathrm{~kg} / \mathrm{cm}^{2}$. Usually the compression intensity of briquette is $45 \mathrm{~kg} / \mathrm{cm}^{2}$ on average. The strength is slightly lower than in the usual operation, but thist is not significant.

Figure 4 shows the trends of zinc, lead, iron, silica and lime contents of a briquette during the melting test, as compared to normal operation. It seemed that no significant difference could be observed during the test operation. However, the following minor differences were observed: the iron and zinc contents decreased at the end of the test operation. This was due to a mechanical problem that occurred in the automatic feed system of iron concentrate. The iron concentrate was added to control the iron content in the slag. This problem caused a shortage of iron feed so that the iron content dropped and, consequently, the zinc concent increased. The typical slag composition is shown in
Table 6. The trends of the zinc and lead contents in slag are shown in Figure 5, and the iron, silica, alumina and lime contents in the slag are shown in Figure 6, respectively, with a comparison of these data with those of commercial operation. The zinc contents of the slag varied between 3 and $7 \%$ and these values were similar to those of normal operation. The lead contents of the slag varied from 0.03 to $0.1 \%$; the same tendency was observed in the normal operation, though just before the end of the test operation both the zinc and the lead contents increased rapidly. This is because the iron feed dropped due to mechanical trouble, as mentioned above; thus the iron content in the briquette decreased and, consequently, the iron content of the slag decreased at the end of the test.

The EPMA test result for slag is shown in Figure 7. The dendritic structure of iron oxide can be seen in the silica base matrix. Also zinc oxide and copper particles are observed. Further inspection is necessary for determination of the slag structure. The practical use of slag is one-of the important issues of this test. To find uses for the slag generated in the SFA treatment, the regulated slag test was carried out to examine the dissolution of heavy metal elements. Based on the

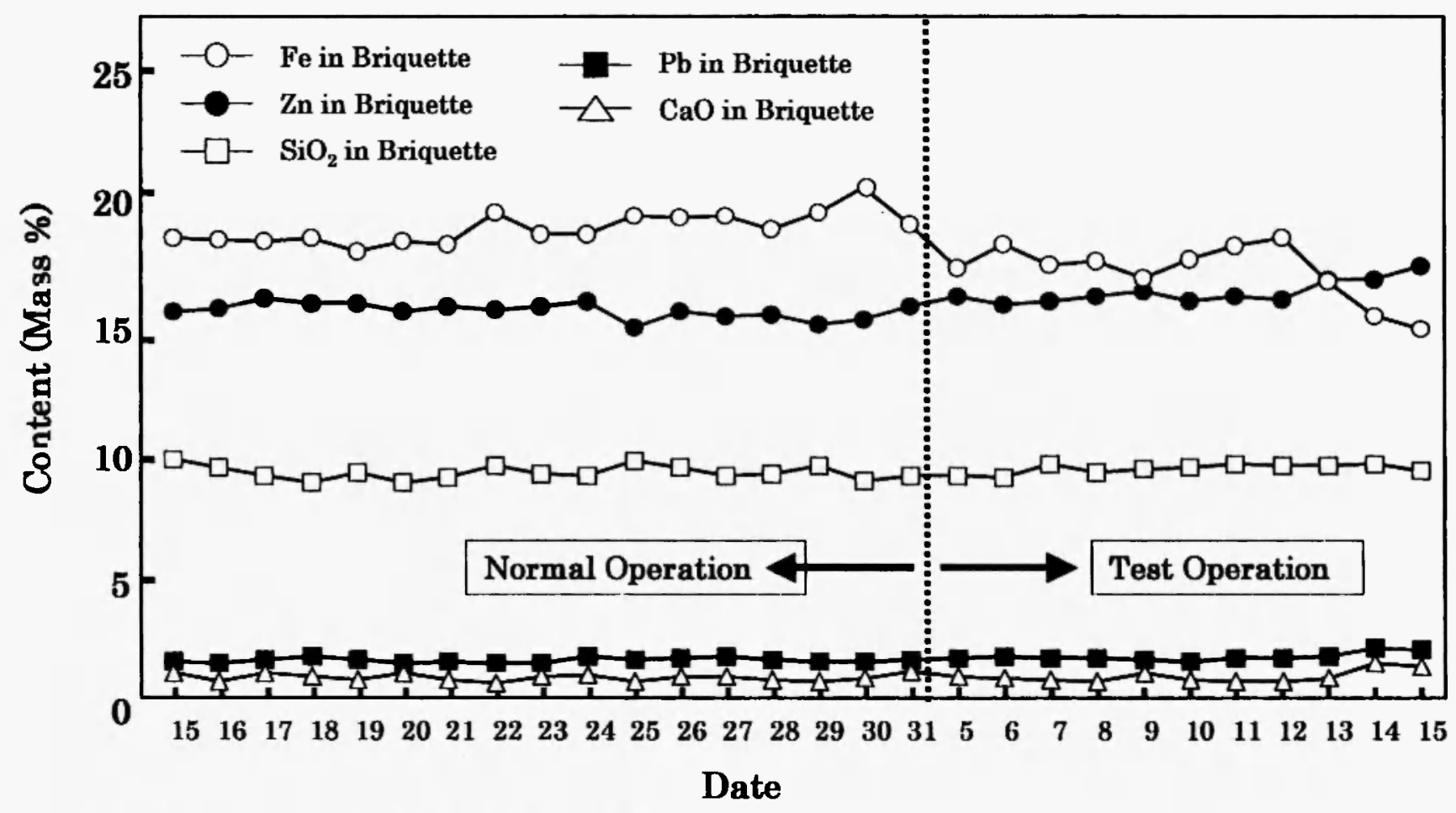

Fig. 4: The trends of $\mathrm{Fe}, \mathrm{Zn}, \mathrm{SiO} 2, \mathrm{~Pb}$ and $\mathrm{CaO}$ content in briquette during test operation and normal operation 
Table 6

Typical composition of slag (mass \%)

\begin{tabular}{lcccccc}
\hline \hline & $\mathrm{Zn}$ & $\mathrm{Pb}$ & $\mathrm{Fe}$ & $\mathrm{SiO}_{2}$ & $\mathrm{CaO}$ & $\mathrm{Al}_{2} \mathrm{O}_{3}$ \\
\hline Test Operation & 3.1 & 0.04 & 34.8 & 20.7 & 5.94 & 6.7 \\
Normal Operation & 3.5 & 0.07 & 35.2 & 21.1 & 5.18 & 5.4 \\
\hline
\end{tabular}

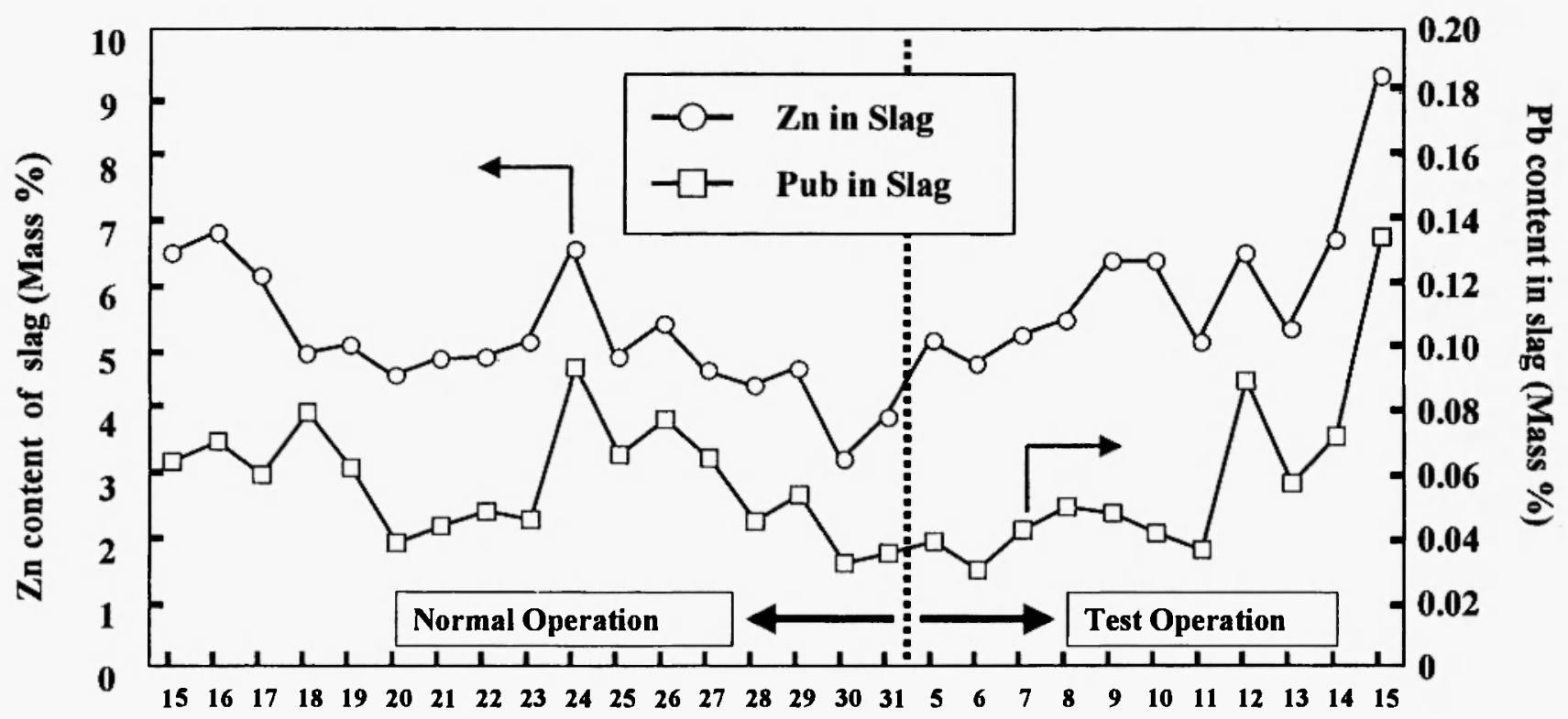

Date

Fig. 5: The trends of $\mathrm{Zn}$ and $\mathrm{Pb}$ content of slag during test operation and normal operation.

extraction test, it is possible to use the slag in the cement industry, similarly to the slag generated in commercial operation.

The chemical reactions in the MF furnace can be considered as follows. Zinc included in EAF dust and SFA form zinc oxide or zinc ferrite $\left(\mathrm{ZnFeO}_{4}\right)$. These zinc compounds are reduced to zinc metal by carbon monooxide and varporize at a higher temperature. The metal vapor tends to be oxidized when the temperature decreased according to equation (2).

$$
\mathrm{Zn}(\mathrm{g})+\operatorname{CO} 2(\mathrm{~g})=\mathrm{ZnO}(\mathrm{s})+\operatorname{CO}(\mathrm{g})
$$

Zinc ferrite is also reduced to zinc metal by carbon monooxide and zinc metal is oxidized again to zinc oxide. Thus this chemical reaction can be considered just as a decomposition of zinc ferrite as shown in reaction (3).

$$
\mathrm{ZnFe}_{2} \mathrm{O}_{4}+\mathrm{CO}=\mathrm{ZnO}+2 \mathrm{FeO}+\mathrm{CO}_{2}
$$

Lead in EAF dust and SFA would form chloride or oxide compounds. Lead is vaporized in the MF furnace and included in the gas phase. Thus they are recovered together with zinc oxide. The zinc oxide is recovered by 


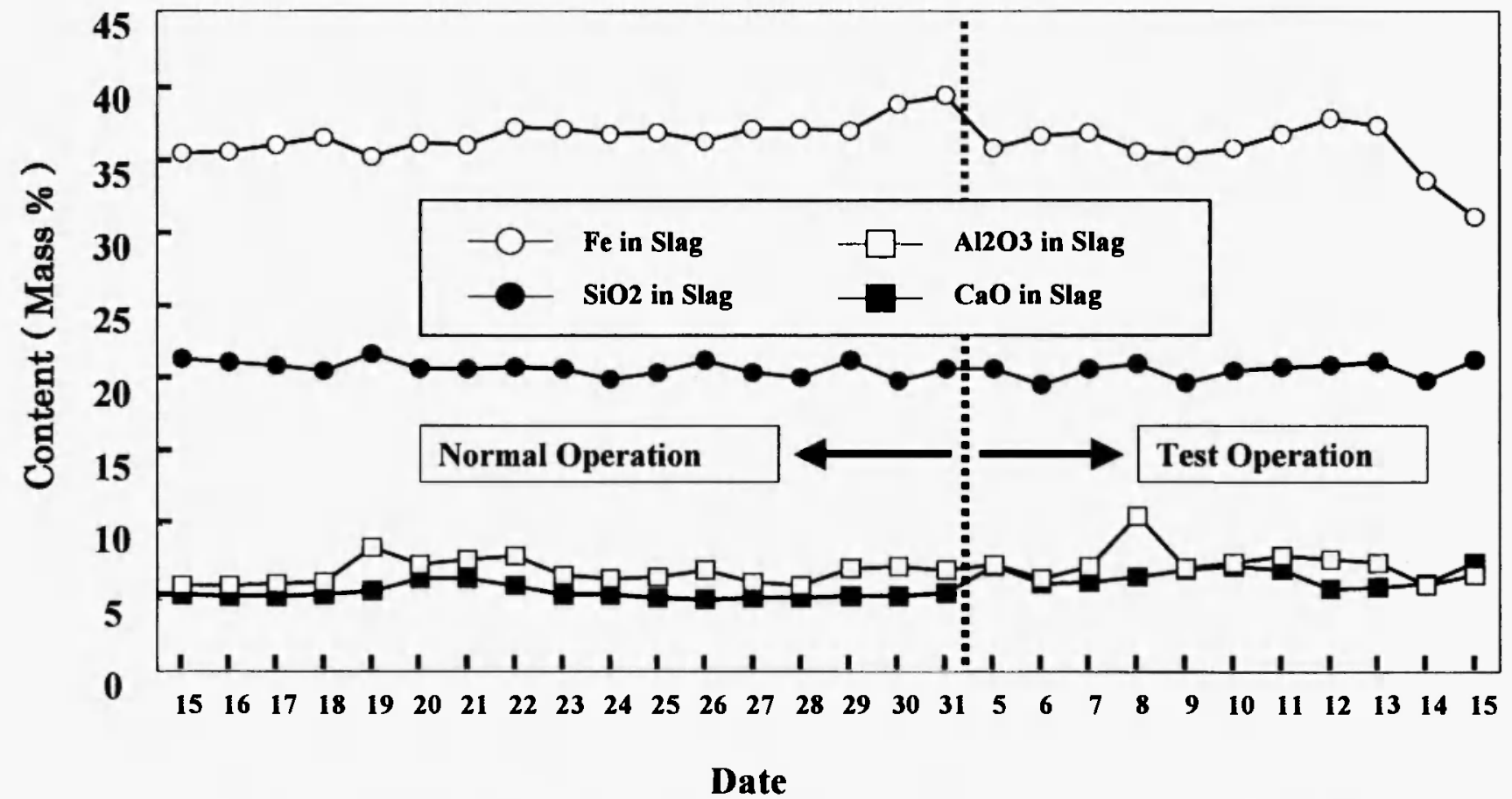

Fig. 6: The trends of $\mathrm{Fe}, \mathrm{SiO} 2, \mathrm{Al} 2 \mathrm{O} 3$ and $\mathrm{CaO}$ of slag during test operation and normal operation.

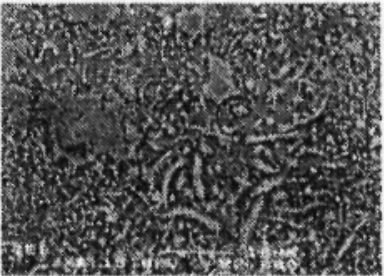

SEM Image

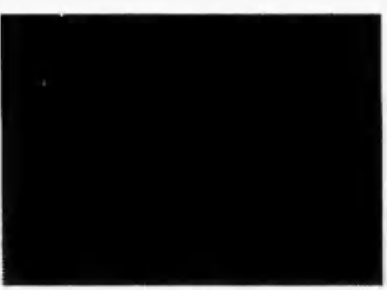

$\mathrm{Pb}$

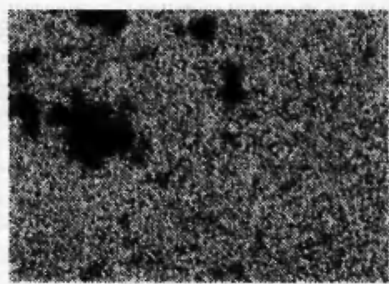

$\mathrm{Ca}$

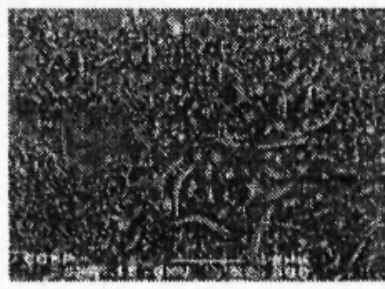

Composition Image

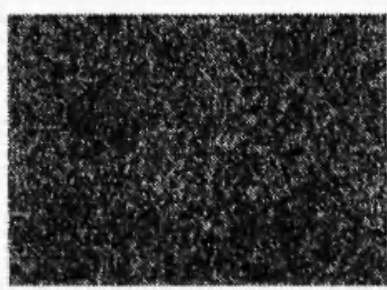

$\mathrm{Fe}$

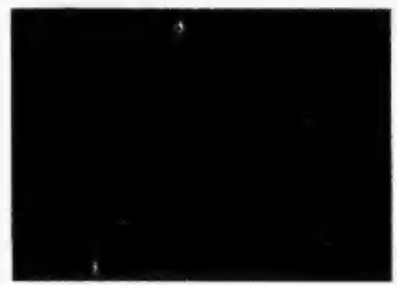

$\mathrm{Cu}$

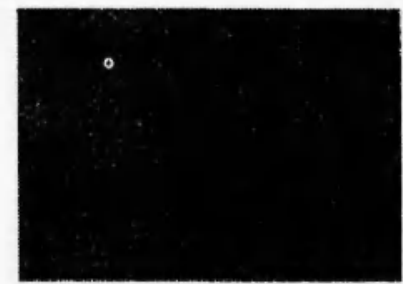

$\mathrm{Zn}$

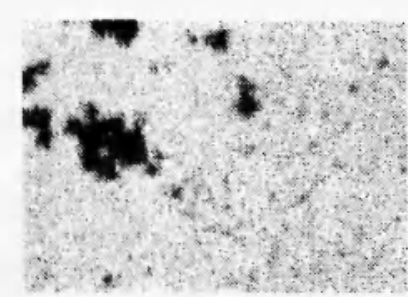

$\mathrm{Si}$

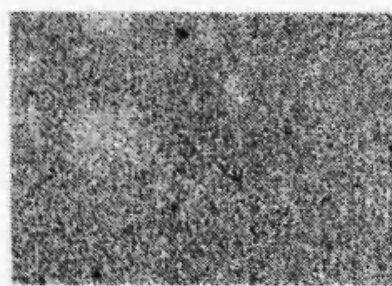

$\mathrm{O}_{2} \quad \frac{}{10 \mu \mathrm{m}}$

Fig. 7: Typical EPMA image of slag during melting test 
the gas washing system and bag house. As it includes a relatively large amount of impurities, it is just a crude zinc oxide. The crude zinc oxide is further treated by a smelting process to produce high purity zinc metal.

One of the main objects of the melting test by using the commercial-scale MF process is to examine the recovery rate of zinc and lead included in SFA. Comparison of the recovery rate of commercial size operation and a laboratory-scale test is very important. In the laboratory test, a high recovery rate was obtained. It is important to make sure that a similar result can be obtained in the commercial-scale operation. The typical chemical composition of recovered crude zinc oxide in the melting test is shown in Table 7 with the data of normal commercial operation for comparison. The zinc content in crude zinc oxide is $64.8 \%$ in the test operation and $65.1 \%$ in the commercial operation. The two zinc contents are quite similar. Regarding the chlorine content, zinc oxide in the test operation contains less chlorine than in the commercial operation. No significant difference has been observed in the contents of other elements between test operation and commercial operation.

The typical X-ray diffraction pattern of recovered crude zinc oxide is shown in Figure 8. Several peaks of zinc oxide, which is the main compound in crude zinc oxide, can be observed. Lead carbonate and lead compounds that contain sodium are also observed.

Table 7

Typical composition of crude $\mathrm{ZnO}$ (mass\%)

\begin{tabular}{lcccccccc}
\hline & $\mathrm{Zn}$ & $\mathrm{Pb}$ & $\mathrm{Cd}$ & $\mathrm{S}$ & $\mathrm{Cu}$ & $\mathrm{Fe}$ & $\mathrm{Ca}$ & $\mathrm{CI}$ \\
\hline Test Operation & 64.8 & 7.22 & 0.15 & 0.27 & 0.12 & 0.82 & 0.09 & 0.12 \\
Normal Operation & 65.1 & 7.73 & 0.16 & 0.43 & 0.09 & 0.95 & 0.11 & 0.25 \\
\hline
\end{tabular}

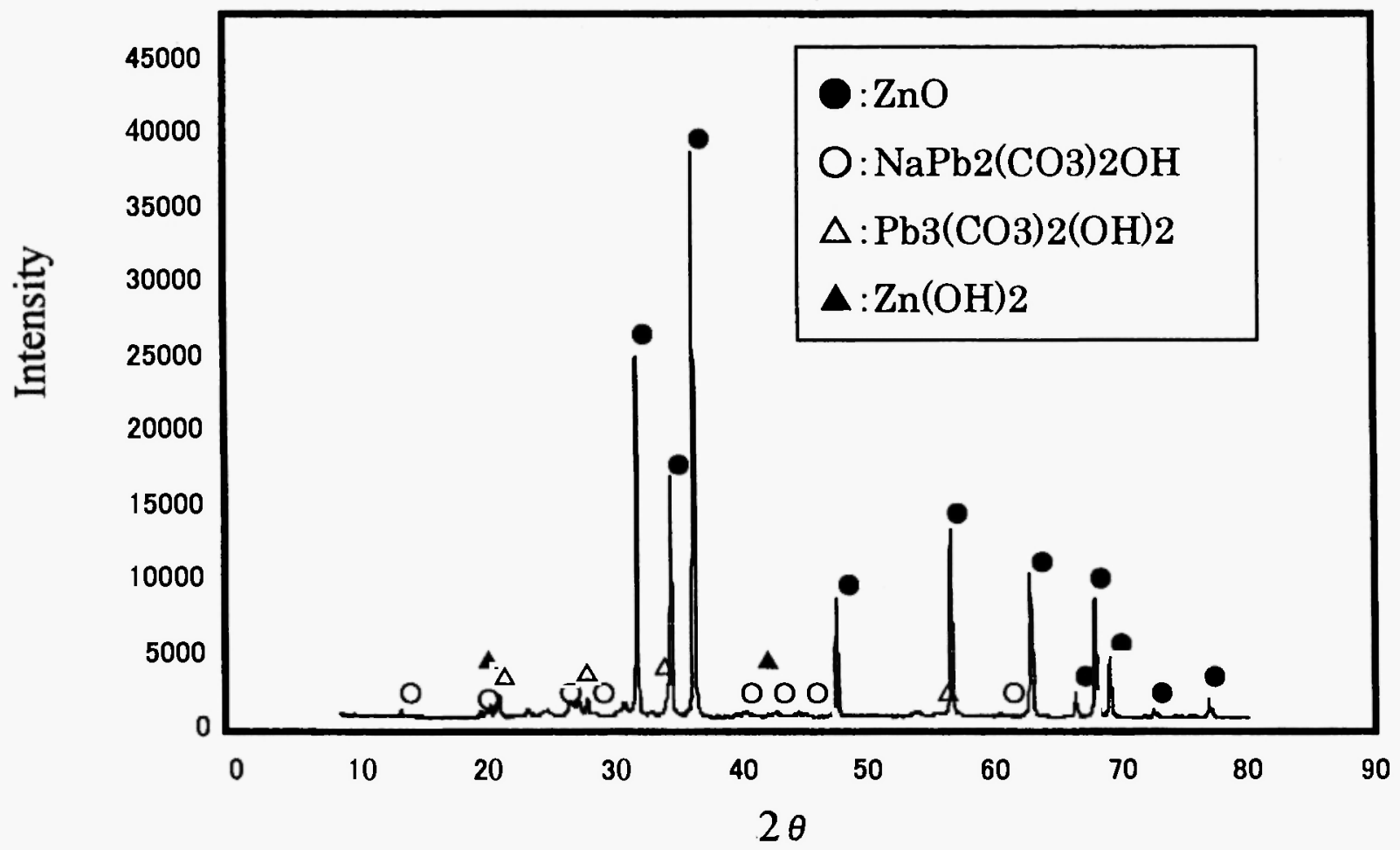

Fig. 8: Typical X-ray diffraction pattern of recovered crude zinc oxide 
Caustic soda is used in the gas washing system for off gas of the MF furnace; thus sodium could be included in crude zinc oxide. Further investigation is necessary to determine the formation mechanism of these compounds.

The recovery rates of heavy metals, such as zinc and lead, are the main concern of this melting test. EAF dust, which is the main raw material for commercial operation, and SFA were provided for this test operation using a commercial-size MF process. The recovery rate of zinc and lead from EAF dust and SFA should be discussed, respectively. It is, however, quite difficult to distinguish the zinc recovered from EAF dust and SFA so that the overall recovery rate is considered. The material balance of zinc and lead during the test operation is shown in Table 8. The overall recovery rate of zinc is $90.1 \%$ and that of lead is $98.7 \%$. These values express the ratio of the recovered metal amount and the charged metal amount. The overall recovery rate is calculated on the basis of Equation (4), where the Ner indicates the amount of recovered zinc from EAF dust and Nrs indicates the recovered zinc from SFA. Nce is the amount of charged zinc included in EAF dust and Nes is the charged zinc included in SFA.

$$
\eta \mathbf{a}=(\mathrm{Nre}+\mathrm{Nrs}) /(\mathrm{Nce}+\mathrm{Ncs})
$$

The target of overall recovery rates of zinc and lead is $\mathbf{9 0 \%}$, which is obtained from the laboratory scale test. The overall recovery rate obtained in the commercial- scale MF process is higher than the target value. Thus treatment of SFA by the commercial size MF process makes it possible to recover zinc and lead at a considerably high recovery rate. The high recovery rates were obtained because of the low zinc and lead contents in slag. Only the heavy metal included in slag is discharged from the system, and other by-products, such as sludge from an effluent plant and dust collected by a hygiene control bag filter, are recharged to the MF process.

The main operating parameters of the MF furnace during the melting test are summarized in Table 9.

The operation during the melting test was quite stable and met with no significant difficulties. The important operating parameters, such as blast air volume, blast air temperature, amount of charge, slag generation, temperature of slag and amount of recovered crude zinc oxide, are quite similar similar to those of normal commercial operation.

Dioxin contents during the test operation were also examined. The detailed data are shown in Table 10. The dioxin content in the briquette was $2.0 \mathrm{ng}-\mathrm{TEQ} / \mathrm{g}$ and $0.54 \mathrm{ng}$-TEQ in the emission gas. The total amount of charged dioxin was $0.806 \mathrm{~g}-\mathrm{TEQ} / \mathrm{d}$ and the exhausted amount was $0.0013 \mathrm{~g}-\mathrm{TEQ} / \mathrm{d}$. Thus the dioxin elimination rate was $99.84 \%$ which is higher than the expected value. Also, the dioxin content in the emission gas is low enough. Thus it can be said that the treatment of SFA by a commercial-size MF process is suitable from the point of view of dioxin elimination as well.

Table 8

Material balance of $\mathrm{Zn}$ and $\mathrm{Pb}$ in test operation

\begin{tabular}{|c|c|c|c|c|c|c|c|}
\hline & \multirow{2}{*}{$\begin{array}{l}\text { Amount } \\
\left(10^{3} \mathrm{~kg} / \mathrm{d}\right)\end{array}$} & \multicolumn{3}{|c|}{$\mathrm{Zn}$} & \multicolumn{3}{|c|}{$\mathrm{Pb}$} \\
\hline & & $\begin{array}{c}\text { Contents } \\
(\%)\end{array}$ & $\begin{array}{c}\text { Net } \\
\left(10^{3} \mathrm{~kg} / \mathrm{d}\right)\end{array}$ & $\begin{array}{l}\text { Distribution } \\
(\%)\end{array}$ & $\begin{array}{c}\text { Contents } \\
(\%)\end{array}$ & $\underset{\left(10^{3} \mathrm{~kg} / \mathrm{d}\right)}{\text { Net }}$ & $\begin{array}{c}\text { Distribution } \\
\text { (\%) }\end{array}$ \\
\hline \multicolumn{8}{|l|}{ In put } \\
\hline Briquette & 402.6 & 15.32 & 61.68 & 100 & 1.60 & 6.44 & 100 \\
\hline \multicolumn{8}{|l|}{ Out Put } \\
\hline Crude $\mathrm{ZnO}$ & 80.0 & 64.8 & 51.86 & 90.1 & 7.22 & 5.78 & 98.7 \\
\hline Slag & 184.2 & 3.1 & 5.71 & 9.9 & 0.04 & 0.07 & 1.3 \\
\hline
\end{tabular}


Table 9

Operation data during melting test

\begin{tabular}{lccc}
\hline & Unit & Test Operation & Normal Operation \\
\hline Blast Air Volume & $\mathrm{m}^{3} / \mathrm{min}$ & 409 & 412 \\
Temperature of Blast Air & $\mathrm{K}$ & 483 & 480 \\
2nd Air Volume & $\mathrm{m}^{3} / \mathrm{min}$ & 94 & 96 \\
Charge Amount & $10^{3} \mathrm{~kg} /$ day & 403 & 428 \\
Slag generation & $10^{3} \mathrm{~kg} /$ day & 184 & 178 \\
Temperature of Slag & $\mathrm{K}$ & 1597 & 1594 \\
Amount of ZnO production & $10^{3} \mathrm{~kg} /$ day & 80.0 & 83.6 \\
\hline
\end{tabular}

Table 10

Dioxin balance during melting test

\begin{tabular}{lccc}
\hline \hline & Amount & DXN Content & DXN Amount \\
\hline Briquette & $403 \mathrm{td}$ & $2.0 \mathrm{ng} \cdot \mathrm{TEQ} / \mathrm{g}$ & $0.806 \mathrm{~g} \cdot \mathrm{TEQ} / \mathrm{d}$ \\
Exhausted gas & $100,000 \mathrm{Nm} 3 / \mathrm{h}$ & $0.54 \mathrm{ng} \cdot \mathrm{TEQ} / \mathrm{Nm} 3$ & $0.0013 \mathrm{~g} \cdot \mathrm{TEQ} / \mathrm{d}$ \\
\hline
\end{tabular}

DXN Emission Rate $\quad 0.16 \%$

DXN Elimination Rate $\quad 99.84 \%$

\section{SUMMARY}

A melting test of secondary fly ash by using the commercial-scale MF process has been carried out. The obtained results are summarized as follows:

(1) Treatment of secondary fly ash is possible by the commercial-size MF process. It was proved that secondary fly ash can be treated up to $10 \%$ of the total amount of raw material without any difficulties in the MF operation.

(2) Elimination of chlorine, which causes problems such as corrosion, is possible by the two-step washing method. The chlorine elimination rate is more than 98\% and the remained chlorine content after washing is approximately $0.2-0.6 \%$.

(3) Heavy metals, such as zinc and lead, can be 
recovered by the MF process. The recovery rate is $90.1 \%$ for zinc and $98.7 \%$ for lead.

(4) The slag generated by treatment of secondary fly ash can be used for the cement industry, based on the result of a leaching test.

(5) The decomposition rate of dioxin in the MF process is more than $99.8 \%$ and the content of dioxin in the exhausted gas is extremely low.

\section{ACKNOWLEDGEMENT}

This research was carried out in the R\&D of technologies for recycling fly ash promoted by MMAJ (Metal Mining Agency of Japan). The authors would like to express their acknowledgement to METI (Ministry of Economy, Trade and Industry) and MMIJ for financial support and useful advice.

\section{REFERENCES}

I. C. Izumikawa, Resources Processing, 143 (3), 149-155 (1996).

2. K. Ookura, K. Murai and M. Umemoto, Resources
Processing, 49 (4), 203-206 (2002).

3. T. Yoshida and H. Nagasaki, Waste Processing and Recycling in Mineral and Metallurgical Industries IV, COM 2001, 2001; pp 137-146.

4. S. Noda, Y. Tatehana and T. Yoshida, Shigen-to Sozai, 2002 (C/D), 277-280 (2002).

5. T. Yoshida, Resources Processing, 48 (2), 114-119 (2002).

6. T. Yoshida, T. Nakamura and M. Maeda, Resources Processing, 50 (2), 57-62 (2001).

7. Y. Hirayama, Shigen-to Sozai, 109 (12), 1118 1120 (1993).

8. Y. Egashira and Y. Murayama, Shigen-to Sozai, 109 (4), 278-28I (1993).

9. M. Suetsugu and H. Nagasaki, Shigen-to Sozai, '94 J-6 17-20 (1994).

10. Y. Tatehana and S. Tanabe, Shigen-to Sozai, BI-9, 33-36 (1997).

II. T. Nakamura and T. Yoshida, CAMP-ISIJ, 6, 6-9 (1997)

12. T. Yoshiida, Kinzoku, 72 (8), 807-816 (2002).

13. S. Yamaguchi and Y. Iguchi, CAMP-ISIJ, 11, 1013 (1997).

14. S. Yamaguchi, Proceedings of Tokyo Symposium on Recycling and Treatment of Metals, 1997; pp. $175=193$. 
